\title{
Bed bug dermatitis, description of two cases in Rio de Janeiro, Brazil
}

\author{
Fred Bernardes Filho ${ }^{1,2}$ \\ João Carlos Regazzi Avelleira ${ }^{1}$ \\ Luna Azulay-Abulafia ${ }^{1,4}$ \\ Teresa Cristina Monte Gonçalves ${ }^{6}$
}

\author{
Maria Victória Quaresma ${ }^{1,2}$ \\ David Rubem Azulay ${ }^{1,2,3}$ \\ Amanda Queiroz Bastos ${ }^{5}$
}

DOI: http://dx.doi.org/10.1590/abd1806-4841.20153214

\begin{abstract}
Bed bugs are hematophagous insects which due to their morphological and biological characteristics are able to easily adapt themselves to human households. The authors describe two cases of dermatitis caused by bed bug bites in the city of Rio de Janeiro, Brazil. Patients presented linear lesions in the usual "breakfast, lunch and dinner" arrangement, suggesting this diagnosis. A visit to their dwellings showed infestation of insects identified as Cimex hemipterus. The knowledge of these insects by the dermatological community will contribute to an accurate diagnosis as well as subsidize the dissemination of information aiming for prevention.
\end{abstract}

Keywords: Arthropods; Bed bugs; Cimicidae; Prurigo

\section{INTRODUCTION}

Cimicidae, or bed bugs, are hematophagous insects that have been associated with man and bats since prehistorical age. ${ }^{1}$ Morphological and biological characteristics such as their minuscule size, dorsoventrally flattened body, absence of developed wings, short life cycle (30 to 45 days) and obligatory hematophagy enable them to hide in crevices and holes, dispersed in a passive way, easing their adaptation to human households, reaching high levels of infestation and acquiring this way economic, medical and epidemiological importance. ${ }^{1,2}$

Global dispersion of these insects increased due to international travel, commerce and migrations. Additionally, the attention turned to the application and indiscriminate use of insecticides for specific pests, not only decreased their predecessors but also made possible their silent proliferation. ${ }^{3}$
In Latin America, the concern with the reemergence of bed bugs was raised in the debates that occurred during the International Lecture on Bed Bugs, where the difficulty of promoting adequate measures became evident considering the lack of knowledge. ${ }^{4}$

In Brazil, Cimex lectularius is marked as having predominant distribution in the south region associated with the intensive European immigration; however, there are foci in tropical cities such as Belo Horizonte. ${ }^{3,5}$ Cimex hemipterus was marked as the species with greater occurrence in Brazil, with tropical distribution in populous centers and rural areas. ${ }^{3}$

The bite of these insects disturbs night rest, causing discomfort when in high rates of infestation. ${ }^{1,3} \mathrm{~A}$ study regarding the efficiency of the feeding process shows that Cimex lectularius is avid and can reach high levels of infestation when compared to Cimex hemipterus. ${ }^{6}$

Received on 17.10.2013.

Approved by the Advisory Board and accepted for publication on 23.11.2013.

* Work performed at Instituto de Dermatologia Professor Rubem David Azulay, Santa Casa da Misericórdia do Rio de Janeiro (IDPRDA-SCMRJ) - Rio de Janeiro (RJ), Brazil.

Financial Support: none

Conflict of Interests: none

Instituto de Dermatologia Professor Rubem David Azulay, Santa Casa da Misericórdia do Rio de Janeiro (IDPRDA-SCMRJ) - Rio de Janeiro (RJ), Brazil.

Pontifícia Universidade Católica do Rio de Janeiro (PUC RJ) - Rio de Janeiro (RJ), Brazil.

Fundação Técnico-Educacional Souza Marques - Rio de Janeiro (RJ), Brazil.

Universidade do Estado do Rio de Janeiro (UERJ) - Rio de Janeiro (RJ), Brazil.

Universidade Federal Rural do Rio de Janeiro (UFRRJ). Instituto Oswaldo Cruz/ Laboratório de Transmissores de Leishmanioses, Setor de Entomologia

Médica e Forense (Fiocruz) - Rio de Janeiro (RJ), Brazil.

Instituto Oswaldo Cruz/ Laboratório de Transmissores de Leishmanioses, Setor de Entomologia Médica e Forense (Fiocruz) - Rio de Janeiro (RJ), Brazil. 
Bites are painless and bed bugs are not noticed unless they are present in great numbers. The pattern of biting distribution is in a linear sequence, in number of three, characteristic, named "breakfast, lunch and dinner" and suggesting the diagnosis. ${ }^{7.8}$

The clinical picture depends on previous exposure to the insect and the degree of immune response of the patient, which can present from cutaneous reactions, whose lesion morphology includes macules, papules and seropapules, pustules, blisters and nodules, to systemic reactions, such as urticaria and anaphylaxis. ${ }^{7,8}$

This report aims at registering the occurrence of bed bug dermatitis in the city of Rio de Janeiro, through the description of two cases.

\section{CASE REPORT}

Case 1: Male patient, 48 years old, presented pruritic lesions on upper and lower limbs with one month of evolution. The onset of symptoms coincided with the move to a new household, in the Lapa neighborhood, Rio de Janeiro, Brazil.

At the dermatological examination, there were excoriated papules and pomphoid lesions (Figure 1A). Some were grouped, in a linear distribution, reminding us of the "breakfast, lunch and dinner" pattern (Figure 1B). Fleas, bed bugs or tick bites hypotheses were raised, however with no confirmation. Upon return, the patient presented bed bugs collected from his house, confirming this way the diagnosis of bed bug dermatitis (dermatosis caused by bed bug bite).

In a visit by the first author to the site, a cluster of nymphs and adults was observed close to the eggs and traces of feces added to the characteristic odor of the bed bugs confirmed the infestation picture (Figure 2 and Video 1). This clustering is explained by the need of insects to search for sites where the body surface is in contact with the substract, characteristic behavior of organisms endowed with positive thigmotaxis., ${ }^{3,9}$

The identification of the specimen, made by the two last authors, was confirmed as belonging to the order Hemiptera, suborder Heteroptera, family Cimicidae, species Cimex hemipterus.

The infestation was notified to the competent health authorities as an unusual event and forwarded to the Environment Monitoring Agency. After fumigation of the house and use of an antihistamine, topical corticoid and icaridin repellant, the patient showed improvement.

Case 2: Male patient, 51 years old, presented diffuse pruritic lesions over the body with 15 days of evolution. He reported that it started two days after he moved to a hotel in the Catete neighborhood, Rio de Janeiro, Brazil. At the dermatological examination, he presented erythematous papules all over the body (Figure 3). Some lesions were grouped in a linear
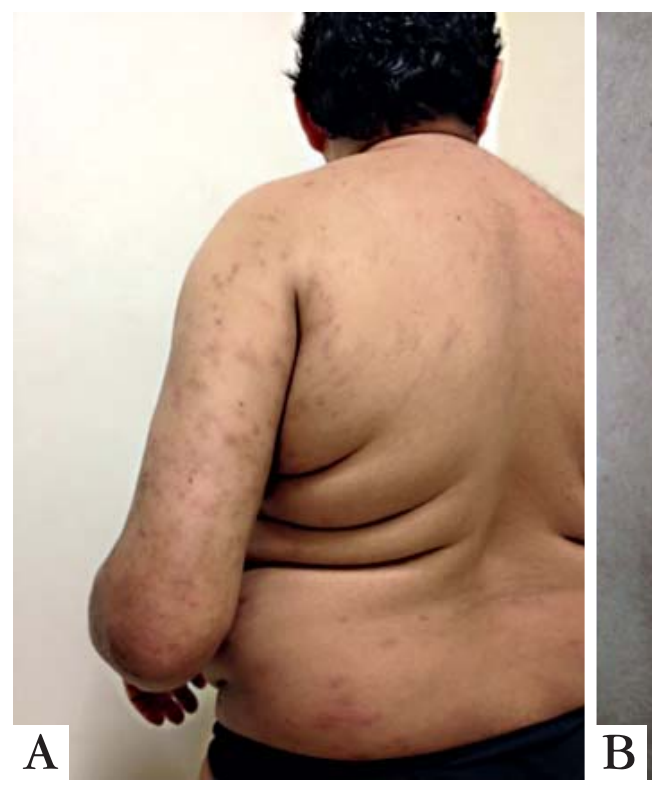

FIGURE 1:

A. Erythematous edematous lesion on the left flank, erythematous papules with excoriated surface and hyperchromic macules on the back and upper left limb; B. Pomphoid lesions over an erythematous base, in a linear distribution 


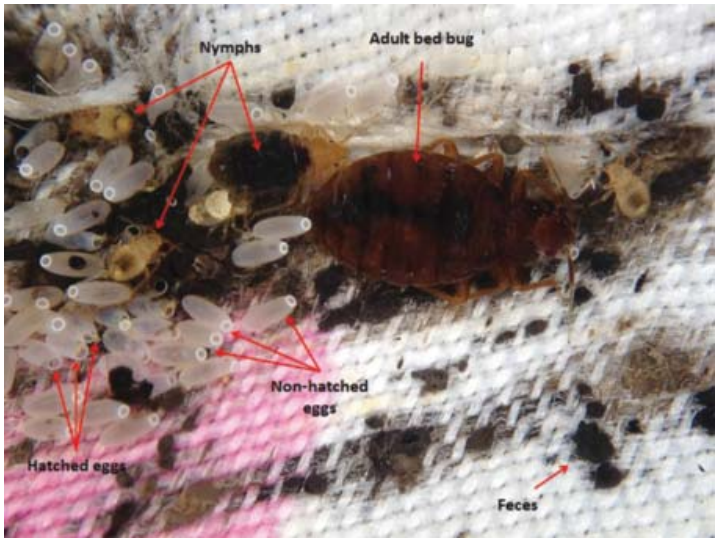

Figure 2: Presence of Cimicidae eggs, nymphs, adult insects and feces over the patient's bed - case 1
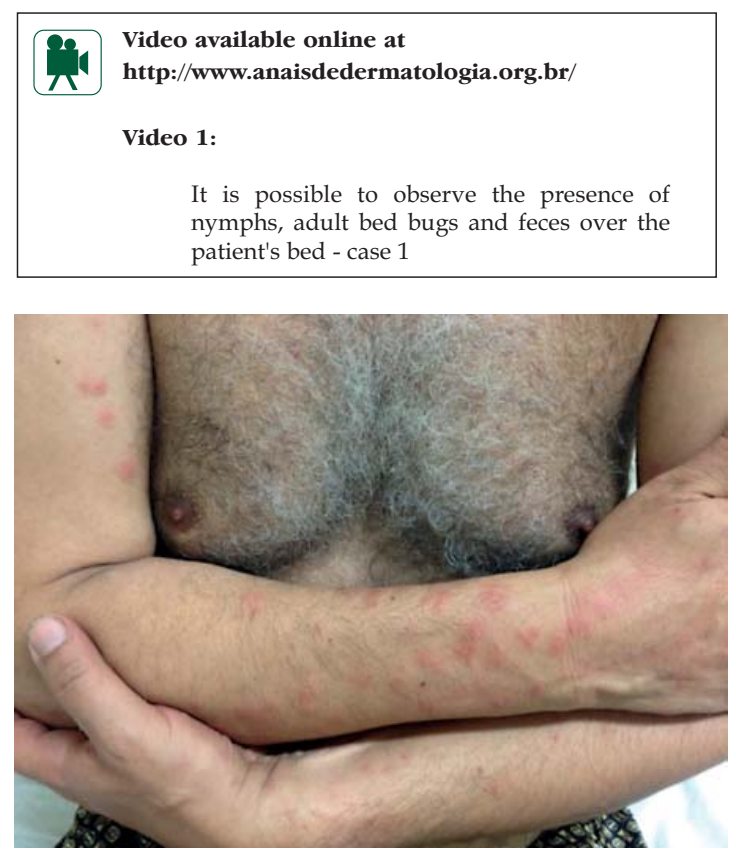

FIGURE 3: Erythematous edematous lesions on upper limbs

sequence, in the "breakfast, lunch and dinner" pattern (Figure 4). In an initial examination were raised hypotheses of bites by bed bugs or fleas.

A visit to the hotel where the patient was lodged was made by the first author, and the presence of Cimicidae eggs, nymphs and adult insects was confirmed, as well as traces of feces on the bed and walls added to the characteristic odor of bed bugs, confirming this way the infestation of the premises and the diagnosis of bed bug dermatitis (Figure 5).

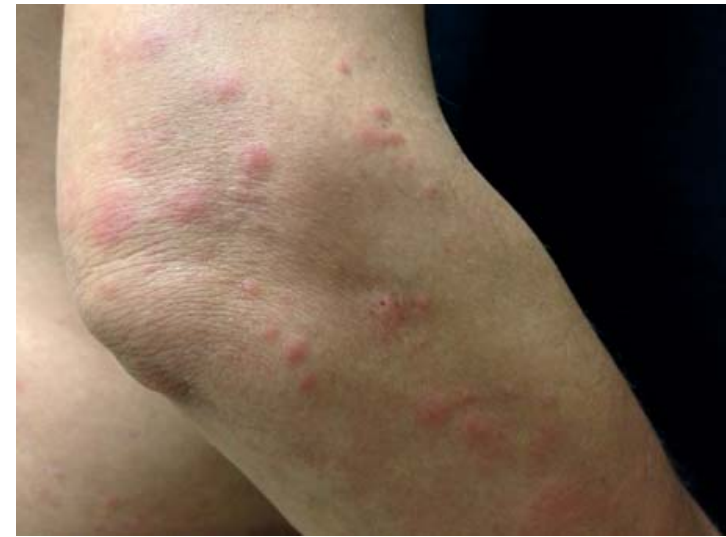

FIGURE 4: Erythematous papules, some with the peculiar "breakfast, lunch and dinner" pattern

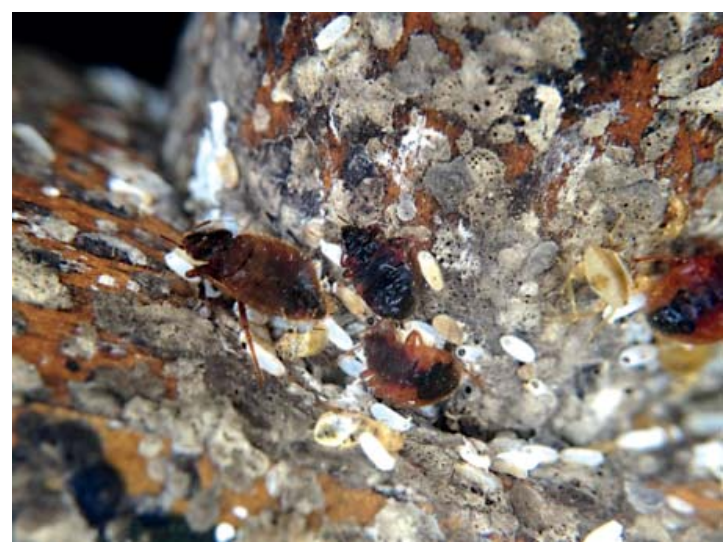

FIGURE 5: Presence of Cimicidae eggs, nymphs, adult insects and feces over the patient's bed - case 2

Specimens were identified, by the two last authors, as Cimex hemipterus, the same species of Case 1.

The infestation was notified and antihistamine, topical corticoid and icaridin repellant were prescribed.

\section{DISCUSSION}

The increase in infestations by bed bugs in the $21^{\text {st }}$ century occurs due to a lack of knowledge of its importance in public health and basic knowledge about the biology of the insect.

The combating of these insects has been done with natural pyrethrins and synthetic pyrethroids due to their low toxicity. However, they do not possess residual effect and present resistance in laboratorial tests. This way, the fight against Cimicidae must be done in a wider context where chemical control must be associated with environmental management, like 
washing bed linen daily with hot water, vacuum clean rooms and bed linens and steam clean furniture, that is, sanitation of housing conditions and household hygiene, associated with information. ${ }^{3,9,10}$

In recent years the increase of infestation cases and negligence with which it is being treated is worrisome. In Brazil, little attention is paid to these insects which can justify them being unknown and consequently the nonexistence of pest control programs. ${ }^{1,3,5,7}$

The presence of some lesions in linear form characterized as "breakfast, lunch and dinner" suggests the occurrence of interruptions and new attempts at feeding, since this is done directly at the blood vessel, whose caliber seems to influence repast. ${ }^{6}$

The cases presented confirm the "silent" occurrence of these insects in neighborhoods of Rio de Janeiro. Thus, it is believed that the knowledge of these insects by the dermatological community will contribute to a precise diagnosis, as well as give subsidies to the dissemination of information, aiming for prevention. $\square$

\section{REFERENCES}

1. Usinger RL. Monograph of Cimicidae (Hemiptera - Heteroptera). Thomas Say Foundation. Vol. 7. Maryland: Entomological Society of America, College Park; 1966. $85 \mathrm{p}$.

2. Reinhardt K, Siva-Jothy MT. Biology of the Bed bugs. Annu Rev Entomol. 2007:52:351-74.

3. Nascimento LGG. Investigação da ocorrência de infestação por Cimicidae (Heteroptera: Cimicomorpha) na Região Metropolitana de São Paulo, no período de 2004 a 2009 [dissertação]. São Paulo (SP): Universidade de São Paulo; 2010. 144p.

4. Coto H. Curso Internacional sobre chinche de cama, organizado por HC Consultores. Revista Plagas Ambiente y Salud. 2011; 48:34.

5. Negromonte MRS, Linardi PM, Nagem RL. Prevalência de Cimex lectularius (Hemiptera: Cimicidae) em uma comunidade de Belo Horizonte. Rev Bras Entomol. 1991;35:715-20.

6. Araujo RN, Costa FS, Gontijo NF, Gonçalves TC, Pereira MH. The feeding process of Cimex lectularius (Linnaeus 1758) and Cimex hemipterus (Fabricius 1803) on different bloodmeal sources. J Insect Physiol. 2009;55:1151-7.

7. Criado PR, Criado RF. Bedbugs (Heteroptera, Cimicidae): an etiology of pruritus to be remembered. An Bras Dermatol. 2011;86:163-4.

8. Goddard J, deShazo R. Bed bugs (Cimex lectularius) and clinical consequences of their bites. JAMA. 2009;301:1358-66.

9. Forattini OP. Os cimicídeos e sua importância em Saúde Pública (HemipteraHeteroptera; Cimicidae). Rev Saúde Públ São Paulo. 1990;24:1-37.

10. Potter MF. The History of Bed Bug Management - With Lessons from the Past. Am Entomol. 2011;54:14-25.

How to cite this article: Bernardes Filho F, Quaresma MV, Avelleira JCR, Azulay DR, Azulay-Abulafia L, Bastos AQ, Gonçalves TCM. Bed bug dermatitis, description of two cases in Rio de Janeiro, Brazil. An Bras Dermatol. 2015;90(2):240-7. 